\title{
What Are The Effects Of Bullying Among Schoolchildren?
}

\author{
Karomat Kilicheva \\ Doctor Of Pedagogy, Department Of General Education, Journalism And Mass \\ Communication University Of Uzbekistan \\ Gavkhar Klicheva \\ Undergraduate Student, Psychology Department, Korea University, Uzbekistan
}

Journal Website:

http://usajournalshub.c

om/index,php/tajssei

Copyright: Original

content from this work

may be used under the

terms of the creative

commons attributes

4.0 licence.

\section{ABSTRACT}

Bullying is a significant problem that society suffers from. However, sometimes such violent behavior is wrongly considered as a "phase of life." It is not a normal life passage, but a repeated violent behavior to show power among peers. Bullying can have severe effects on both victims and bullies as well. This article reviews past findings on school bullying, and considers the bullying as a major risk factor for long-lasting mental and physical health effects.

\section{KEYWORDS}

School bullying, violent behavior, bullies, victims, mental health, physical effects, long-term effects, depression, trauma, suicide

\section{INTRODUCTION}

Bullying found to be the most common form of violence in society. It occurs in schools and communities affecting a large number of youths, which includes the intent of harm and high likelihood of repetition of unwanted aggressive behaviors by peers. In order to address this issue various interventions have been implemented, such as Republic Act 10627, that requires all elementary and secondary schools to adopt policies to prevent bullying in their institutions. Many researchers who focus on student bullying believe that a variety of factors interact to influence bullying behavior, including "families, schools, peer groups, teacher-student relationships, neighborhoods, and cultural expectations." The interaction of these factors can have a positive influence on reducing bullying-if a positive school environment with involved, supportive adults and teachers is created, a positive peer culture 
is established, and school connectedness is reinforced. Researchers also note that bullying generally occurs with the physical or virtual presence of an audience of peers. These bystanders can play an important role in reinforcing bullying behavior through laughter or other encouragement, or in curbing it by speaking out against the behavior.

Despite the fact that school-based bullying prevention programs decrease bullying up to 25\% (McCallion \& Feder, 2013), the National Center for Educational Statistics (2019) reported that one out of every five (20.2\%) students reported for being bullied. Students who are both victims of bullying and involve in bullying are at increased risk for both physical and emotional health problems. Thus, the objective of this paper is to provide an overview of earlier studies in two aspects of bullying amongst school-age children, namely, physical and psychological consequences.

According to various research and experiments, children who experienced bullying are likely to develop severe mental health problems. Victims may gradually sec themselves as outcasts and failures. Studies suggest that victimization has a significant positive correlation with several internalizing disorders, such as anxiety and depression (Brockenbrough et al., 2002; Kaltiala-Heino et al., 2000). This link between victimization and internalizing disorders is particularly strong for adolescent girls and may contribute to the development of eating disorders (Bond, Carlin,Thomas, Rubin, \& Patton, 2001). One study found that attention-deficit disorder was common among victims (Kumpulainen et al., 2001).This connection with attention-deficit disorder is undentandable considering that these children may feel the need to constantly monitor their environment, anxiously anticipating the next victimization episode.

For instance, bullying is closely linked to depression. Depression can cause major issues throughout a child's life. Vanderbilt \& Augustyn (2010) have stated that the likelihood of being diagnosed with a psychiatric disorder in early adulthood is increased if the child has been a victim or has committed bullying. They also highlighted the powerful effect of environment exposure of traumatic behavior. One example is, if one identical twin was bullied and the other was not, the exposed one is at greater risk of psychosomatic symptoms. According to the study conducted by Hansson et al., (2019), respondents of both genders who had been bullied were more likely to have feelings of depression, dizziness, and difficulties falling asleep. Although depression can be shown as one of the major consequences of bullying, Hansson et al. (2019) argued that it can also be shown to affect bullying, such as by impairing a child's social skills. Thus, making them more prone to victimization. Moreover, bullying victims have been reported to often develop self-harm or thinking about suicide in adolescence (Wolke \& Lereya, 2015). Victims were also reported to have trouble making or keeping friends and having social support. Moreover, bullying affects not only victims, but bullies as well. Bullies who realize their behavior have relatively higher levels of depression and distress as compared to those who deny their violent behaviors. Consequences such as higher negative attitudes toward school and even higher risk of dropping out of school can be seen in bullies. They are likely to have more social problems, aggression, and externalizing behaviours. They also tend to have psychiatric diagnoses of anxiety disorders, antisocial personality, and substance abuse. The engagement in high-risk behavior such as using tobacco, alcohol and other drugs is also a possibility. There can be seen a four-times increase in criminal behavior of childhood bullies by early adulthood. They might have issues with having stable relationships and being employed as well (Vanderbuilt \& Augustyn, 2010). Despite the effects that school bullying sometimes has on schoolchildren concurrent with their being bullied, there is limited research on what longterm effects remain once they have left school 
and reached adulthood. This absence in the research is especially puzzling when other relational challenges of childhood, such as child abuse or parental divorce, are known predictors of significant long-term consequences.

School bullying is also correlated with externalizing behaviors such as bullying others and perpetrating acts of violence. Vossekuil, Fein, Reddy, Borum, and Modzeleski (2002), in a report commissioned by the U.S. Secret Service, examined 37 incidents of targeted school shootings and school attacks that occurred in the United States in the period between 1974 and 2000. They found that almost three quarters of the attackers felt persecuted, bullied, threatened, attacked, or injured by others prior to the incident, and in several cases, individual attackers had experienced bullying and harassment that was long-standing and severe.

Furthermore, having numerous psychological difficulties as a result of bullying can lead to both immediate and long-lasting physical effects. Scientists at Harvard University gathered data from 10,000 youngsters living across the United States. Results from the study demonstrated that teenage bullying victims were more likely to develop damaged immune systems, and even experience decreases in their brain size (Schacter, 2020). Besides, scratches, bruises and scars can be the sign of violence. Aside from bumps and scars, a loss of appetite or sleep is common as a result of the anxiety and fear from bullying. According to Clark (2018), through the process of violence, various health related risk factors, such as diabetes, heart disease and even extreme weight gain or weight loss. It should also be noted that past studies showed that both bullies and victims had a higher risk for having poor general health, including pain, headaches and significantly slower recovery from illnesses. On the other hand, one of the long-term effects may include chronic raise in Creactive protein (CRP) levels. Subsequently leading to the increase of risk for cardiovascular disease metabolic disorders and depression as well (Wolke \& Lereya, 2015; Vanderbilt \& Augustyn, 2010). One extreme consequence of peer victimization that has been suggested is suicide. Several cases of suicide by schoolchildren have been attributed to the experience of repeated victimization (see Olweus, 1993; Morita, Soeda, Soeda, \& Taki, 1998). However, because suicidal behavior is commonly multiply determined it is difficult to validate such claims, despite the fact that suicide notes sometimes point to peer victimization as the cause (Morita et al., 1998). There is, nevertheless, some evidence that peer victimization is related to suicidal ideation, that is, the tendency to think about killing oneself. Such thinking is commonly a precursor to committing suicide.

\section{DISCUSSION}

As recommended by the American Medical Association, pediatricians, school psychologists, and other clinicians need additional information about bullies, victims, and their associated health problems. Because young adolescents are reluctant to talk about bullying, health professionals might at times detect symptoms of bullying and victimization before the youth's role in bullying becomes known. However, symptoms may be spotted more easily for some of the groups (ie, bullyvictims) than for others. For example, we found that victims manifest quiet signs of psychological distress that may not be detected easily by teachers. Despite the relatively high self-reports of psychological distress, teachers did not rate victims as having significantly more internalizing problems than students who are uninvolved in bullying. Hence, public-awareness campaigns that not only inform professionals and parents about bullying but also encourage youth to speak out about their problems are needed.

Teachers play a key role in preventing and intervening with bullying at school, yet they receive little if any help or training in how to 
effectively deal with such problems. They lack information, and they are reluctant to intervene when they witness bullying. Although teachers have the benefit of understanding the social context of bullying, they do not necessarily know how to best use this knowledge to intervene. In school settings, bullying and victimization are often considered as personal problems of individual youth rather than problems requiring a collective response. Therefore, it is essential 1) to educate teachers about ways in which schools can alter social norms toward bullying, 2) to assist them to intervene effectively with incidents of bullying, and 3) to work together with clinicians to deal with the symptoms of bullying and victimization.

\section{CONCLUSION}

In summary, bullying is clearly prevalent and impacts children's lives across the globe. Among youth involved in bullying in a community sample of ethnically diverse middle school students, we found that bullies manifest the fewest number of adjustment problems. Specifically, bullies are psychologically stronger than classmates not involved in bullying, and they enjoy high social status among their classmates (although the classmates tend to avoid their company). Victims, on the other hand, suffer not only emotional distress but also social marginalization (ie, classmates avoid them, and they have low social status). Finally, those who both bully and get bullied (ie, bullyvictims) are especially troubled. They are by far the most socially ostracized by their peers, most likely to display conduct problems, and least engaged in school, and they also report elevated levels of depression and loneliness. Even though anti-bullying policies have been huge support in preventing violent behaviors among youths, many school-aged children still abstain from school due to bullying and have to deal with various long-lasting psychological and physical difficulties. To address and prevent this issue, further research studies on youth violence, and systematic interventions, such as school discipline, adult supervision and parent meetings are needed to be developed and implemented.

\section{REFERENCES}

1. Carlisle, N., \& Rofes, E. (2007). School bullying: Do adult survivors perceive long-term effects? Sage Publications, 13(1), 16-26.

2. Clark, M. J. (2018). First year college students' perceptions of the long-term effects of bullying (Unpublished doctoral dissertation). Baker University, Kansas, US.

3. Hansson, E., Garmy, P., Vilhjalmsson, R., \& Kristjansdottir, G. (2019). Bullying, health complaints, and self-rated health among school-aged children and adolescents. Journal of International Medical Research, 48 (2),1-9.

4. Juvonen, J., Graham, S., \& Schuster, M.A. (2006). Bullying among young adolescents: The strong, the weak, and the troubled. Pediatrics, 112(6), 12311237.

5. Kaltiala-Heino, R., Rimpela. P. R., \& Pampela, A. (2000). Bullying at school: An indicator of adolescents at risk for mental disorders. Journal of Adolescence, 23, 661-674.

6. McCallion, G., \& Feder, J. (2013). Student bullying: overview of research, federal initiatives, and legal issues. Congressional Research Service, 1-26. www.crs.gov.

7. Seldin, M., \& Yanez, C. (2019). Student reports of bullying: results from the 2017 school crime supplement to the national crime victimization survey. NCES 054.

8. Schacter, H. L. (2020). Framing bullying as a health risk: null effects on young adults' support for anti-bullying policies. Experimental Results, e27, 1-9. 
The American Journal of Social Science and Education Innovations (ISSN - 2689-100x)

Published: October 31, 2020 | Pages: 422-426

9. Tambawal, M.U., \& Umar, R.M. (2017).

Bullying and its effects on academic performance of secondary school students in Nigeria: implications for counselling. International Journal of Advanced Academic Research, 3 (2),1

10. Vanderbilt, D., \& Augustyn, M. (2010). The effects of bullying. Pediatrics and Child Health 20 (7)

11. Wolke, D. \& Lereya, S.T. (2015). Longterm effects of bullying. Arch Dis Child $100879-885$ 